\title{
Right diaphragmatic iatrogenic hernia after laparoscopic fenestration of a liver cyst: report of a case and review of the literature
}

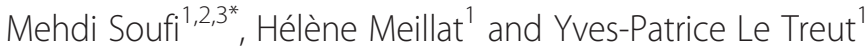

\begin{abstract}
latrogenic right diaphragmatic hernia is very rare. We report the first case of a patient who had a diaphragmatic hernia after laparoscopic fenestration of liver cyst. A herniorrhaphy of the diaphragmatic defect was carried out after reducing the herniated organ. The postoperative course was uneventful. Diaphragmatic hernias are not as common as the traumatic type. Surgeons can easily miss diaphragmatic injuries during the operation especially after laparoscopy. Late diagnosis of iatrogenic diaphragmatic hernias is frequent. Ct scan is helpful for diagnosis. Surgery is the treatment of diaphragmatic hernia at the time of diagnosis, even with asymptomatic patients. The incidence of iatrogenic diaphragmatic hernia after surgery may be reduced if the surgeon checks for the integrity of the diaphragm before the end of the operation. A review of the literature is also performed regarding this rare complication.
\end{abstract}

Keywords: Diaphragm injury, latrogenic right diaphragmatic hernia, Laparoscopic Fenestration of liver cyst, Central tendon of the diaphragm

\section{Introduction}

Liver cysts are benign congenital malformations resulting from isolated aberrant biliary ducts [1]. Laparoscopic fenestration is the treatment of choice for symptomatic simple liver cysts. The indication for surgery should be limited to symptomatic, which involves $5 \%$ to $10 \%$ of all liver cysts [2]. Acquired diaphragmatic hernias are generally the result of blunt or penetrating thoraco-abdominal trauma or iatrogenic injury [3]. Postoperative iatrogenic diaphragmatic hernia right is very rare. We describe a iatrogenic right diaphragmatic hernia after laparoscopic fenestration of right liver cyst.

\section{Case report}

A 61-year-old female with a past medical history of laparoscopic fenestration, one year ago, of a huge right liver benign cyst (Figure 1) presented to our department with right upper abdominal and thoracic pain without

\footnotetext{
* Correspondence: drsoufimehdi@hotmail.fr

'Division of digestive Surgery and transplantation, Hopital de la Conception, Marseille, France

${ }^{2}$ Faculty of medicine, University Mohammed First, Oujda, Morocco

Full list of author information is available at the end of the article
}

vomiting. Chest $\mathrm{x}$-ray showed an elevated right hemidiaphragm. Abdominal examination was normal. Computed tomography CT- scan showed a right posterior diaphragmatic hernia and passive atelectasis due to an ascent of the colon with corresponding mesos and Omentum in the chest cavity (Figures 2 and 3). Laboratory tests showed no abnormality. After coeliotomy through right subcostal incision and reduction of the herniated organs, a defect 10 $\mathrm{cm}$ in diameter was found at the central tendon of the right diaphragm. Direct herniorrhaphy of the diaphragmatic defect was easily carried out. The patient had an uneventful postoperative recovery and the thoracic drain was removed on the second postoperative day. The patient was discharged on the seventh postoperative day.

\section{Discussion}

Surgery is the mainstay of therapy in benign liver cyst. Lin and al [4] first described the technique of fenestration or deroofing of the cysts in 1968 and laparoscopic fenestration was first reported in 1991. Many complications have been reported such as bile leakage, ascites and pleural effusion [5]. In our knowledge, a right diaphragmatic hernia after laparoscopic fenestration of a liver benign cyst had

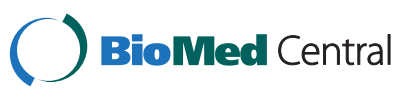




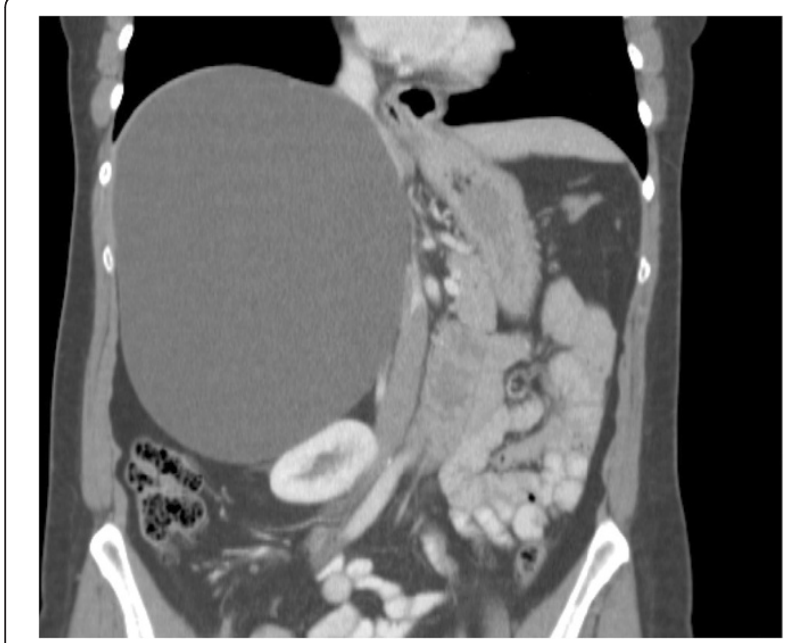

Figure $1 \mathrm{CT}$ scan showing the $20 \times 14 \mathrm{~cm}$ simple liver cyst.

never been reported in the literature review. It's the originality of our case.

The diaphragmatic hernia is a herniation of abdominal structures within the thoracic cavity. It can be either congenital or acquired. Diaphragmatic acquired defects are most commonly traumatic in origin, followed by iatrogenic lesions and spontaneous defects [3]. These are usually on the left side, attributed to the cushioning effect of the liver protecting the right hemidiaphragm [3]. Right-sided traumatic diaphragmatic hernias are more often related to penetrating injuries, but may also occur as a complication of surgery. Iatrogenic right diaphragmatic hernias have been reported after laparoscopic cholecystectomy [6], laparoscopic hepatectomy [7], splenectomy [8], laparoscopic gastric banding [9] splenopancreatectomy [10], gastrectomy [11] and after living

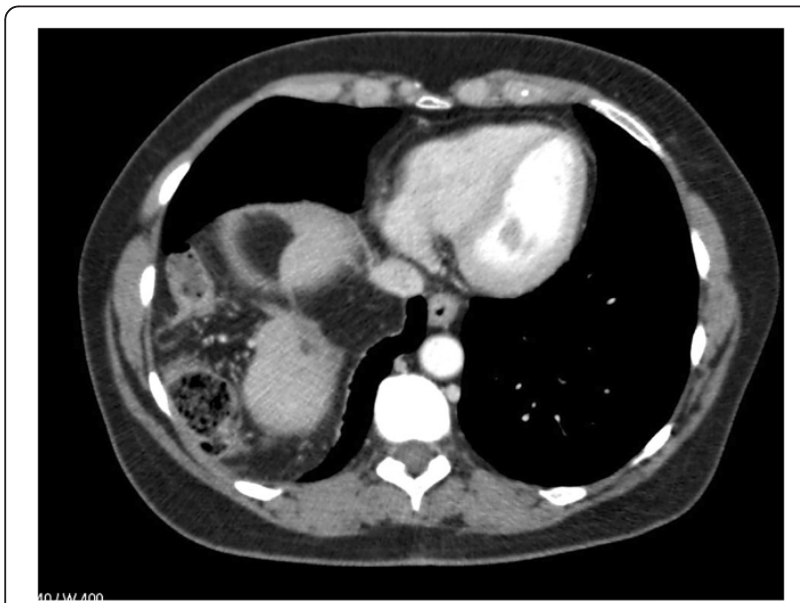

Figure 2 CT scan Transversal computed tomography (CT) showing the loop of colon in the right-sided diaphragmatic hernia.

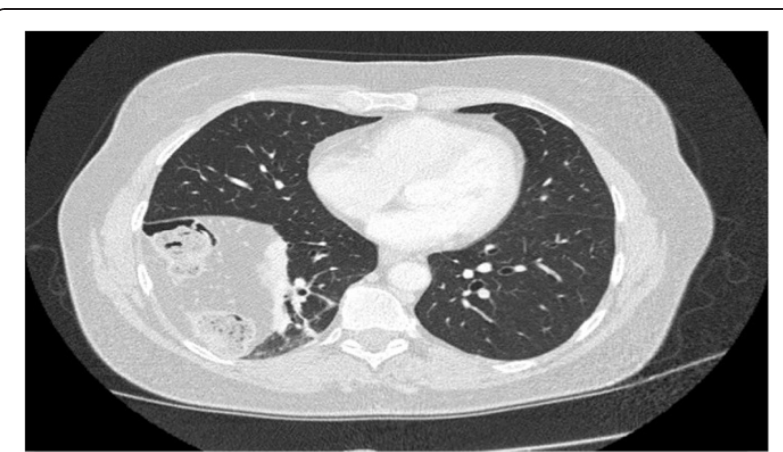

Figure $3 \mathrm{CT}$ scan Transversal computed tomography (CT) showing the loop of colon in the right-sided diaphragmatic hernia.

donor liver transplant [12,13]. Mostly, this complication has been known to develop after esophagectomy and nephrectomy [14-17] (Table 1).

A late presentation of a iatrogenic hernia diaphragm was reported in $5 \%-62 \%$ of cases in different series, with the longest reported delay of 35 years [18].

Grasping instrument and electrocautery and dissection near of the diaphragm may cause diaphragmatic injuries after surgery. The energy generated by these instruments especially the ultrasonic activated scissor can provoke a weak point in the diaphragm [11].

That's why surgeons must be careful handling the instruments, thermofusion and ultrasonic dissector during laparoscopy $[6,19]$. A small diathermy injury may not be observed during surgery; any such defect in the diaphragm is likely to increase in size as a result of the gradient of pressure between the abdominal and pleural cavities. This is what probably happened in our patient who had a $10 \mathrm{~cm}$ defect.

Patients with large diaphragmatic defects can have critical problems shortly after surgery due to cardiorespiratory disturbances. Unexplained pain in post operative is not specific but should suspect this complication. Other patients may be asymptomatic or have vague symptoms, which may delay the diagnosis. Our patient presented pain one year after the first surgery. The diagnosis of a cyst recurrence was suspected firstly but not the diagnosis of a diaphragmatic hernia.

The clinical features are usually chronic symptoms such as upper abdominal and lower chest pain, nausea, dyspnea, and reflux after meals, which may develop into an acute presentation with severe epigastric pain, vomiting, and intestinal obstruction $[11,19]$.

The radiological diagnosis is often complex and includes several imaging modalities [18]. Chest radiograph is a good screening examination, but only $50 \%$ of patients show an abnormality $[18,19]$. CT scan is the best imaging modality to diagnose diaphragmatic hernias. Its sensitivity is high but specificity is only $50 \%$ for the right side [20,21]. Surgery 
Table 1 The characteristics of the reported cases of iatrogenic diaphragmatic hernia

\begin{tabular}{|c|c|c|c|c|c|c|c|}
\hline Case & Age & Gender & $\begin{array}{l}\text { Time to } \\
\text { diagnosis }\end{array}$ & Initial surgical procedure & $\begin{array}{l}\text { Localisation } \\
\text { of defect }\end{array}$ & Surgical procedure & Year \\
\hline $1[6]$ & 53 & Women & 6 weeks & Laparoscopic cholecystectomy & Right & Thoracotomy & 1999 \\
\hline $2[7]$ & 31 & Women & 9 months & Laparoscopic hepatectomy & Left & Thoracotomy & 2003 \\
\hline $3[8]$ & 35 & Women & 24 months & Laparoscopic gastric banding & Left & Laparotomy approach & 2008 \\
\hline $4[9]$ & 60 & Man & 6 weeks & Splenectomy for Hydatid cyst & Left & Thoracotomy & 2010 \\
\hline $5[10]$ & 51 & Man & 4 years & Splenopancreatectomy & Left & Thoracotomy & 2006 \\
\hline $6[11]$ & 81 & Women & 8 months & Laparoscopy assisted total Gastrectomy total & Left & Laparoscopy & 2012 \\
\hline $7[12]$ & 44 & Man & 28 months & Living donor liver transplant & Right & Laparotomy approach & 2010 \\
\hline $8[13]$ & 54 & Man & 3 years & Right donor and Hepatectomy & Right & Thoracotomy & 2006 \\
\hline $9[14]$ & 50 & Man & 6 months & Nephrectomy & Left & Thoracotomy & 1995 \\
\hline $10[15]$ & 74 & Man & 5 years & Nephrectomy & Right & Thoracotomy & 1996 \\
\hline $11[16]$ & 69 & Man & 3 years & Nissens procedure & Left & Thoracotomy & 1996 \\
\hline $11[18]$ & 39 & Women & 35 years & Transthoracic oesophagogastrectomy & Left & Laparotomy & 1988 \\
\hline $12[19]$ & 47 & Women & 1 day & Nephrectomy & Left & Thoracotomy & 2008 \\
\hline $13[24]$ & 60 & Man & 4 months $p$ & Lung resection & Left & Thoracotomy & 2010 \\
\hline $14[25]$ & 19 & Women & 2 years & Lower lobectomy & Left & Laparoscopy & 2000 \\
\hline Current study & 61 & Women & 1 year & Laparoscopic fenestration right liver benign cyst & Right & Laparotomy & 2012 \\
\hline
\end{tabular}

is the treatment of diaphragmatic hernia at the time of diagnosis, even in asymptomatic patients.

Some authors think that the thoracotomy is the elective surgical approach that can correct anatomical restoration of the chest and abdominal cavity especially when it is the approach during the initial surgical procedure [22-24]. Though patients who had a thoracotomy approach had the longest length of stay with a higher need for postoperative mechanical ventilation than those undergoing an abdominal approach after diaphragmatic hernia repair. Paul et al. found that the thoracotomy approach is an independent predictor of the development of a pulmonary embolism [25]. We think that laparotomy through a right subcostal incision is a more efficient approach into the abdominal cavity.

Treatment by laparoscopy is feasible with a shorter length of stay. This approach is especially used in left diaphragmatic hernia repair $[11,26]$.

Because of liver bulk, right side hernia is not amenable to laparoscopic repair, with a high level of conversion. However some authors described this approach with success [27]. In our patient, the hernia was in the right side of hepatic vein, this was the reason we preferred a laparotomy approach.

Herniated contents are reduced, the muscular defect is treated and an endothoracic drain is placed [28]. In some cases a bowel resection might be needed in case of ischemia. The mortality following emergency surgery for these cases rises between $20 \%$ and $80 \%$. [14,15].

The majority of these defects can be repaired safely with non-absorbable sutures without the need for a prosthetic mesh $[21,28]$. With an increase in the number of laparoscopic surgery performed, it is likely that this complication will increase. It is therefore important that surgeons be aware of this potentially serious complication by looking to the diaphragm in the end of each surgical procedure [29]

\section{Conclusion}

Iatrogenic herniation of abdominal contents after laparoscopic fenestration of liver cyst is a rare complication. Iatrogenic diaphragmatic injury can be missed during surgery. Surgeon must take precaution to avoid it by precise dissection when using the instruments during surgery. The incidence of iatrogenic diaphragmatic hernia after surgery may be reduced if a final look of diaphragm is systematically realized at the end of each laparoscopic operation.

\section{Consent}

Written informed consent was obtained from the patient for publication of this case report and accompanying images.

\section{Abbreviation \\ CT: Computed tomography.}

\section{Competing interest}

All Authors does not have any financial relationship with any organization. No benefits in any form have been received or will be received from a commercial party related directly or indirectly to the subject of this article. All authors have the full control of all primary data and that they agree to allow the journal to review their data if requested. All authors contributed to the realization of this manuscript. The authors declare that they have no competing interests. 


\section{Authors' contributions}

All of the authors were involved in the preparation of this manuscript.MS write the manuscript coordinated the team, and helped in literature research. HM was an assistant surgeon and made substantial contributions to conception and design. YPL performed the operation and edited the final version of the manuscript. All authors read and approved the final manuscript.

\section{Author details}

'Division of digestive Surgery and transplantation, Hopital de la Conception, Marseille, France. ${ }^{2}$ Faculty of medicine, University Mohammed First, Oujda, Morocco. ${ }^{3}$ Division of digestive Surgery, Oujda CHU, University Mohammed first, Faculty of medicine Bp 4847 Oujda University, 60049, Oujda, Morocco.

Received: 16 September 2012 Accepted: 20 December 2012 Published: 3 January 2013

\section{References}

1. Fabiani P, Mazza D, Toouli J, Bartels AM, Gugenheim J, Mouiel J: Laparoscopic fenestration of symptomatic nonparasitic cysts of the liver. Br J Surg 1997, 84:321-322.

2. Farges $\mathrm{O}$, Bismuth $\mathrm{H}$ : Fenestration in the management of polycystic liver disease. World J Surg 1995, 19:25-30.

3. Crandall M, Popowich D, Shapiro M, West M: Posttraumatic hernias: historical overwiew and review of the literature. Am Surg 2007, 73:845.

4. Lin TY, Chen CC, Wang SM: Treatment of non-parasitic cystic disease of the liver: a new approach to therapy with polycystic liver. Ann Surg 1968, 168:921-927.

5. Bai $X L$, Liang $T B$, Y J J, Wang WL, Shen Y, Zhang M, Zheng SS: Long-term results of laparoscopic fenestration for patients with congenital liver cysts. Hepatobiliary Pancreat Dis Int 2007, 6:600-603.

6. Armstrong PA, Miller SF, Brown GR: Diaphragmatic hernia seen as a late complication of laparoscopic cholecystectomy. Surg Endosc 1999, 13:817-818.

7. Sugita M, Nagahori K, Kudo T, Yamanaka K, Obi Y, Shizawa R, Yoshimoto N, Shimada H: Diaphragmatic hernia resulting from injury during microwaveassisted laparoscopic hepatectomy. Surg Endosc 2003, 17:1849-1850.

8. Ajarmeh K, Qassed N, Amireh A, Shuraydeh Z, Shabaneh M, Khraisat K: latrogenic left diaphragmatic hernia as a complication of hydatid splenectomy. J R Med Serv 2010, 17(Supp 1):75-78.

9. Boyce S, Burgul R, Pepin F, Shearer C: Late presentation of a diaphragmatic hernia following laparoscopic gastric banding. Obes Surg 2008, 18(11):1502-1504.

10. Testini M, Vacca A, Lissidini G, Di Venere B, Gurrado A, Loizzi M: Acute intrathoracic gastric volvulus from a diaphragmatic hernia after left splenopancreatectomy: Report of a case. Surg Today 2006, 36(11):981-984.

11. Suh Y, Lee JH, Jeon H, Kim D, Kim W: Late onset iatrogenic diaphragmatic hernia after laparoscopy-assisted total gastrectomy for gastric cancer. J Gastric Canc 2012, 12(1):49-52.

12. Perwaiz A, Mehta N, Mohanka R, Kumaran V, Nundy S, Soin AS: Right-sided diaphragmatic hernia in an adult after living donor liver transplant: a rare cause of post-transplant recurrent abdominal pain. Hernia 2010, 14:547-549.

13. Hawxby AM, Mason DP, Klein AS: Diaphragmatic hernia after right donor and hepatectomy: a rare donor complication of partial hepatectomy for transplantation. Hepatobiliary Pancreat Dis Int 2006, 5:459-461.

14. Axon PR, Whatling PJ, Dwerryhouse S, Forrester-Wood CP: Strangulated iatrogenic diaphragmatic hernia: a late complication. Eur J Cardiothorac Surg 1995, 9:664-666.

15. Peterli R, Ackermann C, Tondelli P: Incarcerated diaphragmatic hernia as a sequela of iatrogenic diaphragmatic defect. 2 case reports. Chirurg 1996, 67:1050-1052

16. Sancho LM, Paschoalini Mda S, Jatene FB, Rodrigues Junior AJ: latrogenic diaphragmatic hernia following abdominal esophagogastrofundoplication: report of a case. Rev Hosp Clin Fac Med Sao Paulo 1996, 51:250-252.

17. Aly A, Watson Dl: Diaphragmatic hernia after minimally invasive esophagectomy. Dis Esophagus 2004, 17:183-186.

18. Johnson CD, Ellis H: Acquired hernias of the diaphragm. Postgrad Med J 1988, 64:317-321.

19. De Meijer VE, Vles WJ, Kats E, den Hoed PT: iatrogenic diaphragmatic hernia complicating nephrectomy: top-down or bottom-up? Hernia 2008, 12:655-658.
20. Peer SM, Devaraddeppa PM, Buggi S: Traumatic diaphragmatic hernia our experience. Int J Surg 2009, 7:547-549.

21. Dapri G, Himpens J, Hainaux B, Roman A, Stevens E, Capelluto E, Germay O, Cadière GB: Surgical technique and complications during laparoscopic repair of diaphragmatic hernias. Hernia 2007, 11:179-183.

22. Singh M, Singh G, Pandey A, Cha CH, Kulkarni S: Laparoscopic repair of iatrogenic diaphragmatic hernia following radiofrequency ablation for hepatocellular carcinoma. Hepatol Res 2011, 41(11):1132-1136.

23. Divisi D, Imbriglio G, De Vico A, Crisci R: Right diaphragm spontaneous rupture: a surgical approach. Sci World J 2011, 5:1036-1040.

24. Fukami T, Konoeda C, Kitano K, Sakamoto M, Sano A, Yoshida Y, Mura T, Nakajima J: latrogenic diaphragmatic hernia following partial resection of the lung via video-assisted thoracoscopy. Kyobu Geka 2010, 63(13):1151-1154.

25. Paul S, Nasar A, Port JL, Lee PC, Stiles BC, Nguyen AB, Altorki NK, Sedrakyan A: Comparative analysis of diaphragmatic hernia repair outcomes using the nationwide inpatient sample database. Arch Surg 2012, 147:607-612.

26. Shah S, Matthews BD, Sing RF, Heniford BT: Laparoscopic repair of a chronic diaphragmatic hernia. Surg Laparosc Endosc Percutan Tech 2000, 10(3):182-186.

27. Rossetti G, Brusciano L, Maffettone V, et al: Giant right post-traumatic hernia: laparoscopic repair without mesh. Chir Ital 2005, 57:243-246.

28. Guner A, Ozkan OF, Bekar Y, Kece C, Kaya U, Reis E: Management of delayed presentation of a right-side traumatic diaphragmatic rupture. World J Surg 2012, 36:260-265.

29. Potter SR, Kavoussi LR, Jackman SV: Management of diaphragmatic injury during laparoscopic nephrectomy. J Urol 2001, 165:1203-1204.

doi:10.1186/1749-7922-8-2

Cite this article as: Soufi et al:: Right diaphragmatic iatrogenic hernia after laparoscopic fenestration of a liver cyst: report of a case and review of the literature. World Journal of Emergency Surgery 2013 8:2.

\section{Submit your next manuscript to BioMed Central and take full advantage of:}

- Convenient online submission

- Thorough peer review

- No space constraints or color figure charges

- Immediate publication on acceptance

- Inclusion in PubMed, CAS, Scopus and Google Scholar

- Research which is freely available for redistribution

Submit your manuscript at www.biomedcentral.com/submit
Biomed Central 